\title{
Cutaneous manifestations of anti-neutrophil cytoplasmic antibody associated vasculitis
}

\author{
Mona Abdel-Halim', Ayman Mahmoud ${ }^{2}$, Gaafar Ragab ${ }^{2}$ \\ 'Department of Dermatology, Dermatopathology Unit, Faculty of Medicine, Cairo University, Cairo 11562, Egypt. \\ ${ }^{2}$ Department of Internal Medicine, Rheumatology and Clinical Immunology Unit, Faculty of Medicine, Cairo University, Cairo \\ 11562, Egypt. \\ Correspondence to: Prof. Gaafar Ragab, Department of Internal Medicine, Faculty of Medicine, Cairo University, Twin Tower \\ D3E, 26 July corridor, Zayed City, Giza 12588, Egypt. E-mail: gragab@kasralainy.edu.eg
}

How to cite this article: Abdel-Halim M, Mahmoud A, Ragab G. Cutaneous manifestations of anti-neutrophil cytoplasmic antibody associated vasculitis. Vessel Plus 2022;6:8. https://dx.doi.org/10.20517/2574-1209.2021.40

Received: 26 Feb 2021 First Decision: 6 Apr 2021 Revised: 18 Apr 2021 Accepted: 20 Apr 2021 Published: 17 Feb 2022

Academic Editor: Luca Quartuccio Copy Editor: Yue-Yue Zhang Production Editor: Yue-Yue Zhang

\begin{abstract}
Anti-neutrophil cytoplasmic antibody (ANCA)-associated vasculitis (AAV) is a distinct group of systemic vasculitis with severe multi-organ involvement. It includes three types: granulomatosis with polyangiitis (GPA), eosinophilic granulomatosis with polyangiitis (EGPA), and microscopic polyangiitis (MPA). Cutaneous manifestations are present at the time of presentation in around $35 \%$ of cases and are more frequently encountered in EGPA than in GPA or MPA. They can also occur during the course of the disease or mark a disease relapse. They can be classified into specific or non-specific according to the presence or absence of vasculitis, whether or not associated with granuloma, in skin biopsies. The most common presentation of vasculitic skin lesions in AAV is palpable purpura. Other manifestations include hemorrhagic blisters, tender subcutaneous nodules, livedo reticularis/racemosa, painful ulcers that may mimic pyoderma gangrenosum (PG), and digital gangrenes. A wide range of non-specific cutaneous manifestations can occur in association with AAV including urticarial rash, prurigo, sterile pustules, and oral lesions. The presence of cutaneous lesions is usually associated with severe organ involvement and systemic manifestations. Since skin lesions in AAV can occur in other types of vasculitis and in other disorders, attributing them to AAV requires meticulous clinical, laboratory, and serological correlation. Awareness of cutaneous lesions of AAV is important for all physicians working in the field of systemic vasculitis as a skin biopsy may provide an easy clue to diagnose $A A V$ in such cases.
\end{abstract}


Keywords: Anti-neutrophil cytoplasmic antibody, vasculitis, granulomatosis with polyangiitis, eosinophilic granulomatosis with polyangiitis, microscopic polyangiitis, cutaneous, purpura, ulcers

\section{INTRODUCTION}

Anti-neutrophil cytoplasmic antibody (ANCA)-associated vasculitis (AAV) is a clinically distinct group of severe multi-organ vasculitis involving small/medium-sized vessels with subsequent tissue damage. Vessels involved are mainly capillaries, arterioles, and venules but small/medium-sized arteries and veins may also be involved. According to clinical features and presence or absence of asthma and/or granulomatosis, this group includes three diseases: granulomatosis with polyangiitis (GPA), eosinophilic granulomatosis with polyangiitis (EGPA), and microscopic polyangiitis (MPA) ${ }^{[1]}$.

As in many other systemic disorders, cutaneous involvement is commonly encountered in AAV and may be the first presenting sign of the disease. Variable incidences among different reports are noted. According to recently published data from a large international multi-center study, cutaneous manifestations at time of presentation were present in $35 \%$ of AAV cases and were found to be more frequently encountered in EGPA (47\%) when compared to GPA and MPA (34\% and $28 \%$, respectively ${ }^{[2]}$. Other studies reported skin manifestations occurring during the course of the disease in $47 \%$ of GPA cases, $44 \%$ of MPA cases, and $40 \%$ of EGPA cases $^{[3-5]}$. Skin lesions can also mark a disease relapse ${ }^{[6]}$.

The spectrum of skin lesions in AAV is wide and more than 50\% of cases will have more than one type of skin lesions at a certain time ${ }^{[2,6]}$. Accordingly, knowledge of such lesions and collaboration with dermatologists is important for physicians providing care for systemic vasculitis patients.

Being an easily accessible organ for biopsy, the presence of skin lesions may provide an easy way to confirm the presence of vasculitis by routine histopathological and immunofluorescence studies. This can be further substantiated by clinical examination and laboratory investigations including ANCA testing.

\section{THE CLINICOPATHOLOGIC SPECTRUM OF CUTANEOUS LESIONS IN AAV}

Understanding the underlying histopathological changes is important to appreciate the wide spectrum of skin lesions encountered in AAV. Accordingly, skin manifestations in AAV can be classified as specific or non-specific. The term specific does not mean lesions that occur exclusively in AAV, but rather skin lesions that show histopathological evidence of vasculitis with or without granulomas when biopsied. They can still be encountered in other systemic disorders or other forms of vasculitis. On the other hand, non-specific skin lesions do not show histopathological features of vasculitis or granuloma. They may show features reflecting the various morphologies of these lesions or just show non-specific perivascular lymphocytic infiltrates $^{[7]}$. In either case, attributing skin lesions to AAV needs careful clinical, laboratory, and serological correlations and exclusion of all other possible causes of similar lesions or their mimics.

In all three types of AAV, cutaneous vasculitis presents as leukocytoclastic vasculitis with fibrinoid necrosis of vessel walls (usually involving small dermal vessels and less commonly medium-sized subcutaneous ones), perivascular infiltrates (mainly composed of neutrophils), endothelial cell swelling, red cell extravasation, neutrophil fragmentation, and neutrophil dust ${ }^{[8]}[$ Figure 1]. Vasculitis with granulomatosis (perivascular collections of epithelioid histiocytes and/or giant cells-perivascular granulomatosis) is a rare finding in skin lesions of GPA and EGPA ${ }^{[0]}$. The term vasculitis with granulomatosis is better used to describe such finding than granulomatous vasculitis since the term granulomatous vasculitis usually implies the presence of granulomas inside the vessel walls as in giant cell vasculitis and Takayasu's arteritis, which is 

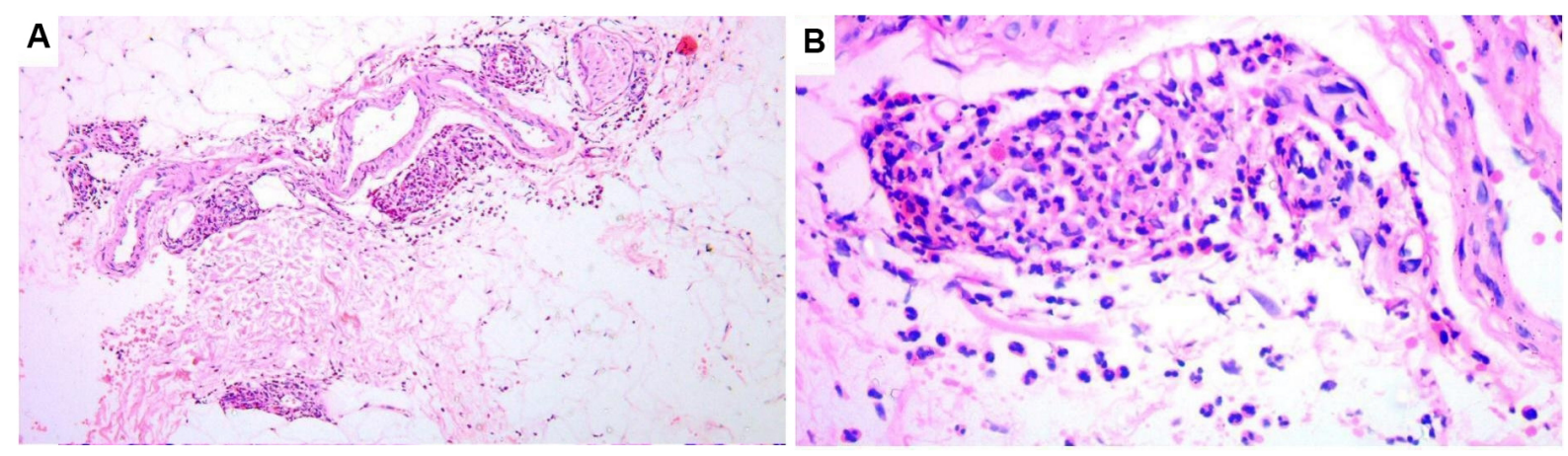

Figure 1. Photomicrograph depicting histopathological features of a purpuric lesion in a case of microscopic polyangiitis. (A) Leukocytoclastic vasculitis involving small vessels in the subcutaneous fat ( $H \& E$, original magnification 40x). (B) A higher magnification image showing details of leukocytoclastic vasculitis: fibrinoid necrosis of the vessel wall, neutrophils surrounding and infiltrating the vessel, extravasated erythrocytes, and nuclear dust (H\&E, original magnification 100×).

not the case in GPA and EGPA ${ }^{[10-12]}$. Direct immunofluorescence (DIF) will show immunoglobulin (usually IgM) and complement $\mathrm{C} 3$ deposition around the walls of blood vessels in 70\% and 50\% of cases of GPA and EGPA, respectively ${ }^{[8,13]}$. DIF is usually negative in MPA apart from possible few deposits of IgM and $\mathrm{C} 3^{[4,14]}$.

Granulomas which are extravascular in nature (usually necrobiotic palisading or necrotizing granulomas surrounding foci of collagen necrobiosis or necrosis) such as those encountered in internal organs in GPA and EGPA cases can be seen in skin lesions of these patients. They usually occur in association with vasculitic changes $^{[8]}$. The necrobiotic/necrotic zones may be large and geographic in appearance [Figure 2]. A special type of granulomatous reaction known as palisaded neutrophilic and granulomatous dermatitis (PNGD) (sometimes referred to as Winkelmann's granuloma, Churg-Strauss granuloma, or interstitial granulomatous dermatitis) can develop in association with $\mathrm{AAV}^{[15,16]}$. It is characterized histopathologically by various changes according to their age. Early lesions show intense neutrophil infiltrates, karyorrhectic debris, and frank leukocytoclastic vasculitis, whereas late lesions show necrobiotic collagen changes, palisades of histiocytes, and small granulomas eventually associated with areas of fibrosis ${ }^{[17]}$ [Figure 3].

In addition, skin lesions in EGPA characteristically show large amount of eosinophils in the infiltrate surrounding the inflamed blood vessels, in the dermis (tissue eosinophilia), and in the context of the granulomas admixed with histiocytes and multi-nucleated giant cells ${ }^{[8,13]}$ [Figure 4]. Such finding explains the pruritus frequently expressed by these patients.

\section{Clinical presentation of specific skin lesions in AAV}

Common clinical presentations of vasculitic skin lesions in AAV

AAV mainly involves small dermal vessels, hence the clinical presentation is predominantly that of palpable purpura/petechia usually involving the lower limbs ${ }^{[8,18]}$ [Figure 5]. This was reported in $15 \%$ of cases of $\mathrm{AAV}^{[2]}$. When deep subcutaneous vessels are involved, patients present with livedo reticularis/racemosa, papules, or nodules on purpuric background, as well as tender subcutaneous nodules ${ }^{[19]}$. Severe cases may show widespread extension, hemorrhagic blisters, and painful ulcerations secondary to skin necrosis ${ }^{[6,7]}$ [Figures 6 and 7]. Splinter hemorrhages have also been reported ${ }^{[2]}$. In GPA and EGPA, vasculitic lesions may involve the face and scalp ${ }^{[5,8,20]}$ [Figure 8].

Vasculitic lesions in AAV typically follow a chronic relapsing course with recurrent attacks lasting for weeks to months that generally improve with treatment directed to the associated deep organ in focus. 


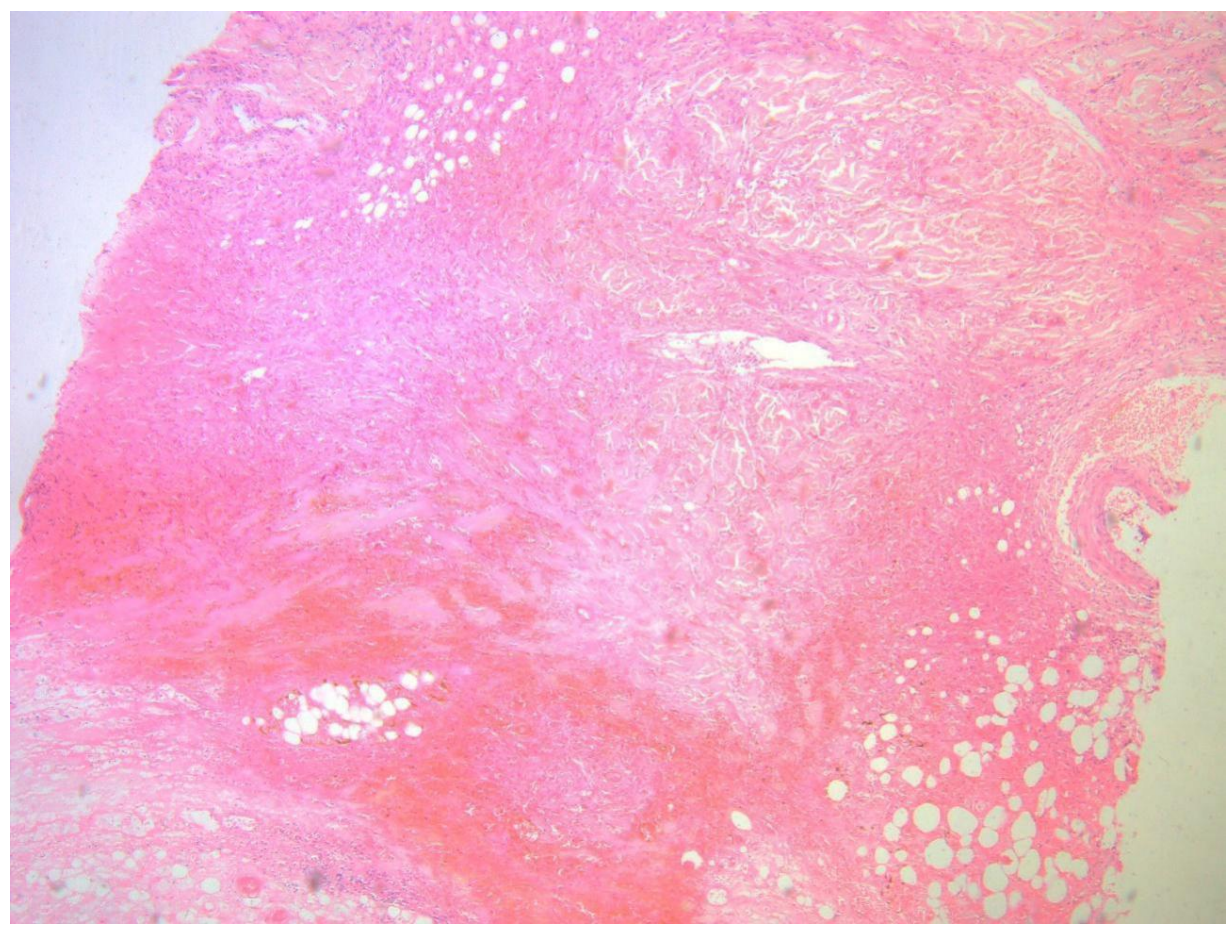

Figure 2. Photomicrograph depicting large zones of necrobiosis/necrosis in the dermis from a case of granulomatosis with polyangiitis (H\&E, original magnification 40x) (courtesy of the Dermatopathology Unit, Dermatology Department, Cairo University).

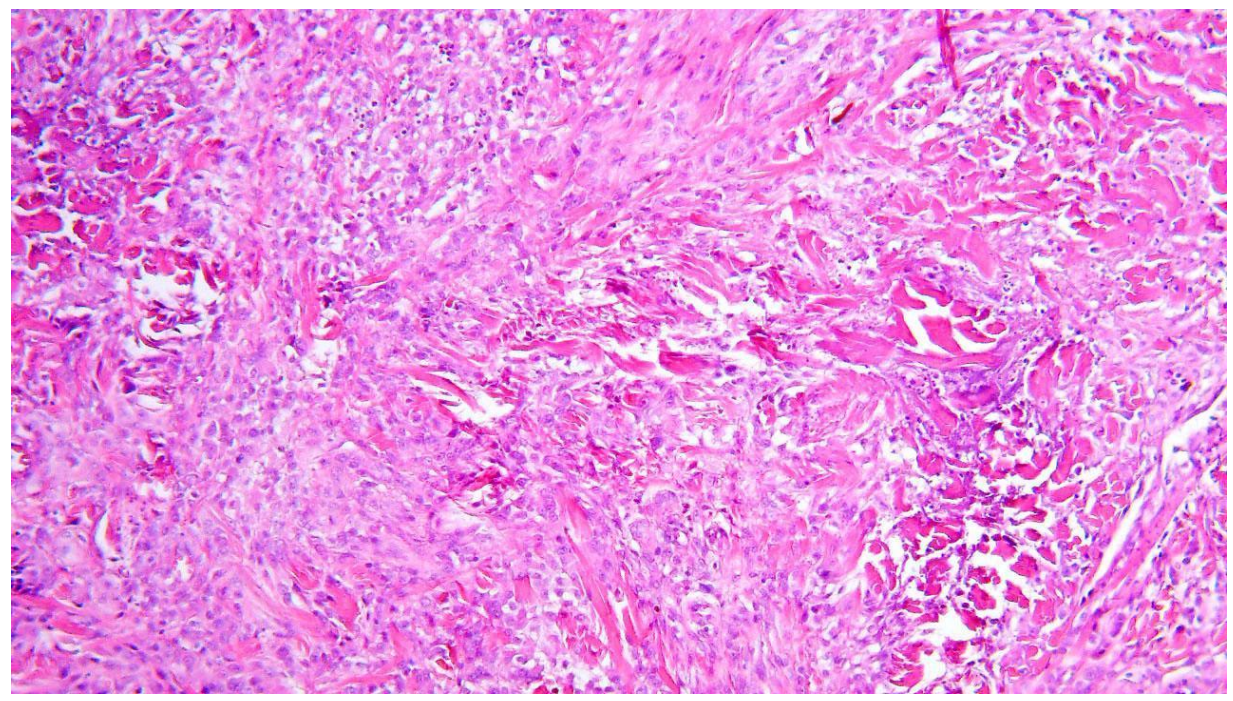

Figure 3. Photomicrograph depicting features of palisaded neutrophilic and granulomatous dermatitis in a case of granulomatosis with polyangiitis: interstitial histiocytes and neutrophils as well as foci of necrobiotic collagen (H\&E, original magnification 100x).

Rare or unusual clinical presentations of vasculitic skin lesions in $A A V$

GPA patients may develop pyoderma gangrenosum (PG)-like ulcers characterized by being large, intensely painful with undermined edges ${ }^{[8,21,22]}$. Several pediatric cases of GPA have been reported with PG-like ulcers mainly presenting on the face as the initial presenting manifestation of the disease. This can even precede the classic systemic symptoms ${ }^{[23-27]}$ [Figure 9]. Localized variants of GPA may present with long standing recalcitrant ulcerative skin lesions mainly localized to the face and upper respiratory tract mucosa ${ }^{[28,29]}$. 


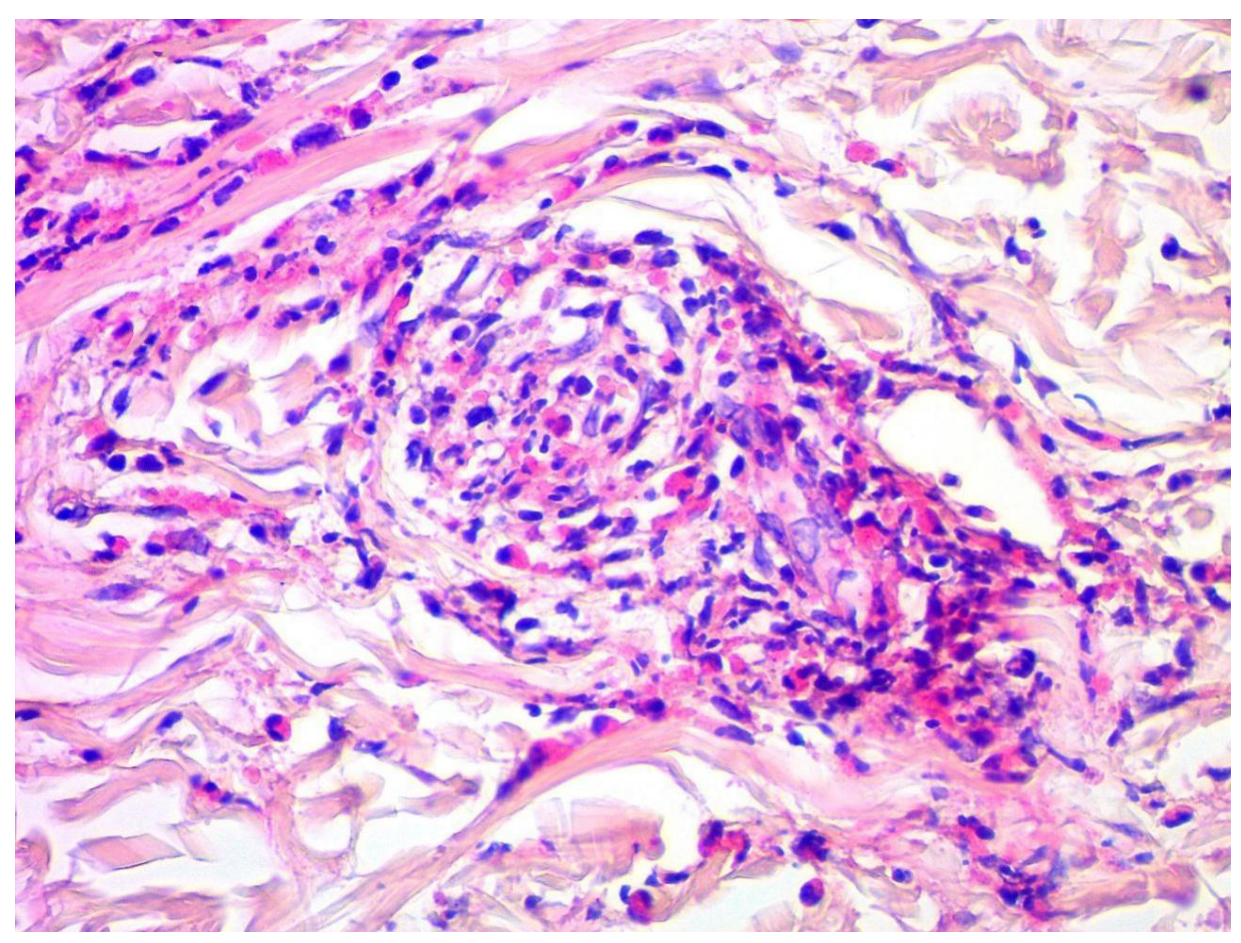

Figure 4. Photomicrograph depicting extensive amount of eosinophils infiltrating and surrounding an inflamed small dermal blood vessel from a case of eosinophilic granulomatosis with polyangiitis (H\&E, original magnification 100x) (courtesy of the Dermatopathology Unit, Dermatology Department, Cairo University).

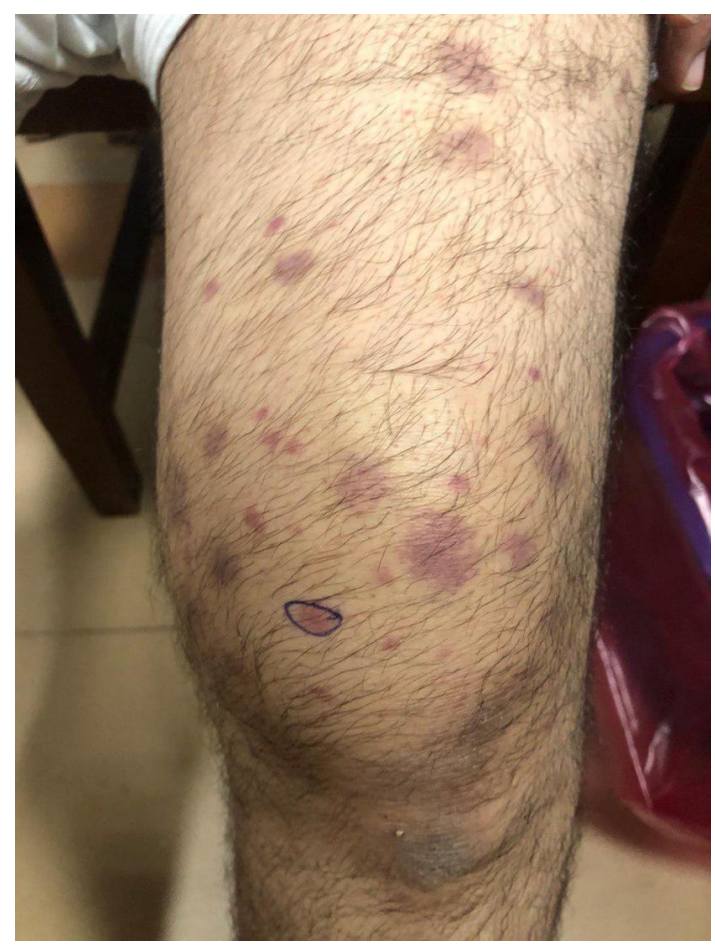

Figure 5. Palpable purpura and petechiae in a patient with microscopic polyangiitis. 


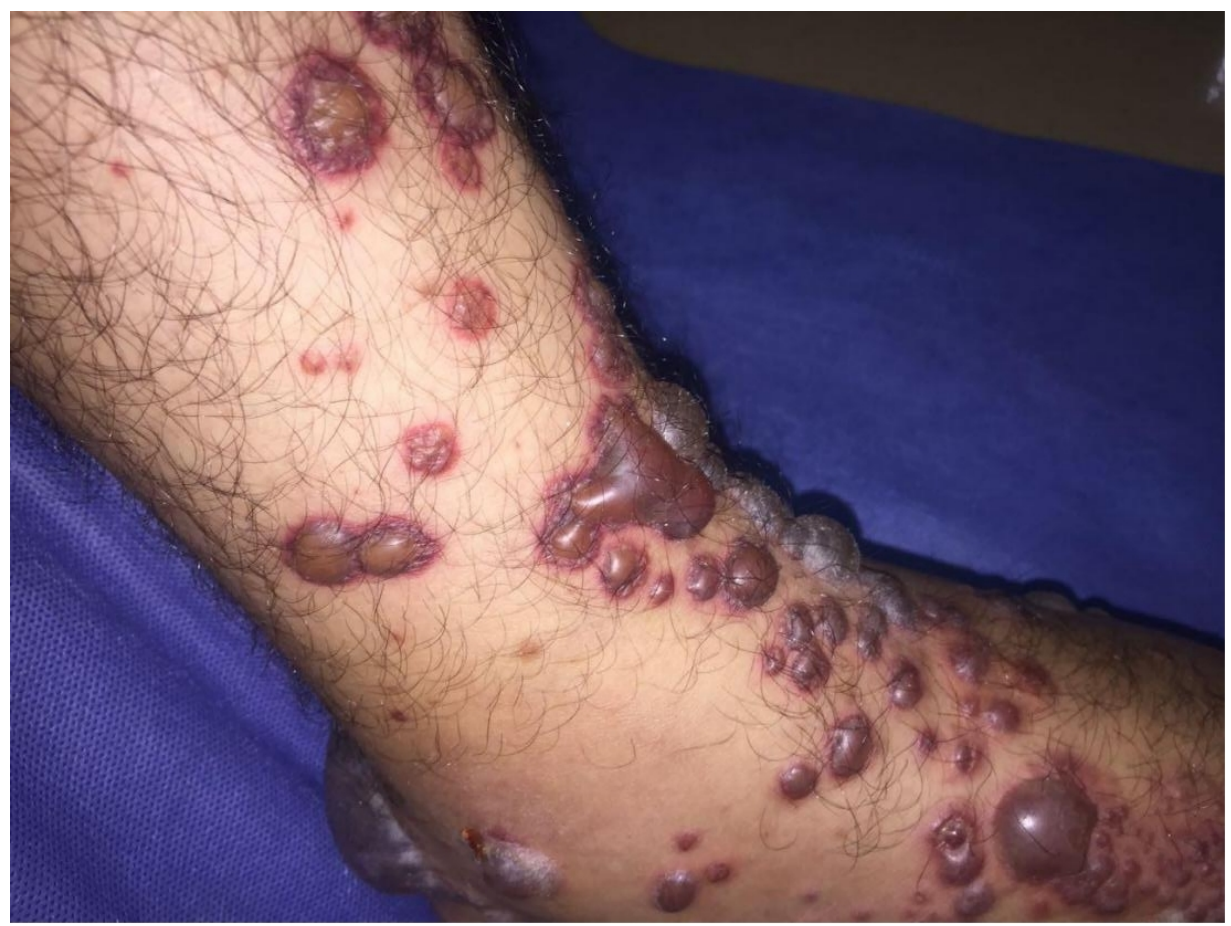

Figure 6. Hemorrhagic blisters as a manifestation of severe cutaneous vasculitis in a patient with granulomatosis with polyangiitis.

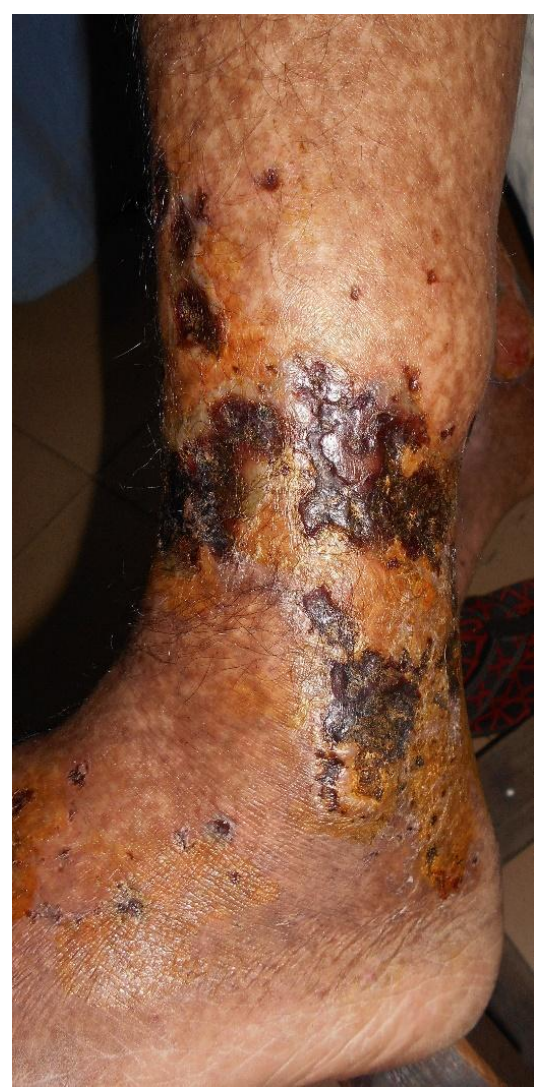

Figure 7. Skin necrosis and ulceration in a patient with granulomatosis with polyangiitis (courtesy of the Dermatology Department, Cairo University) 


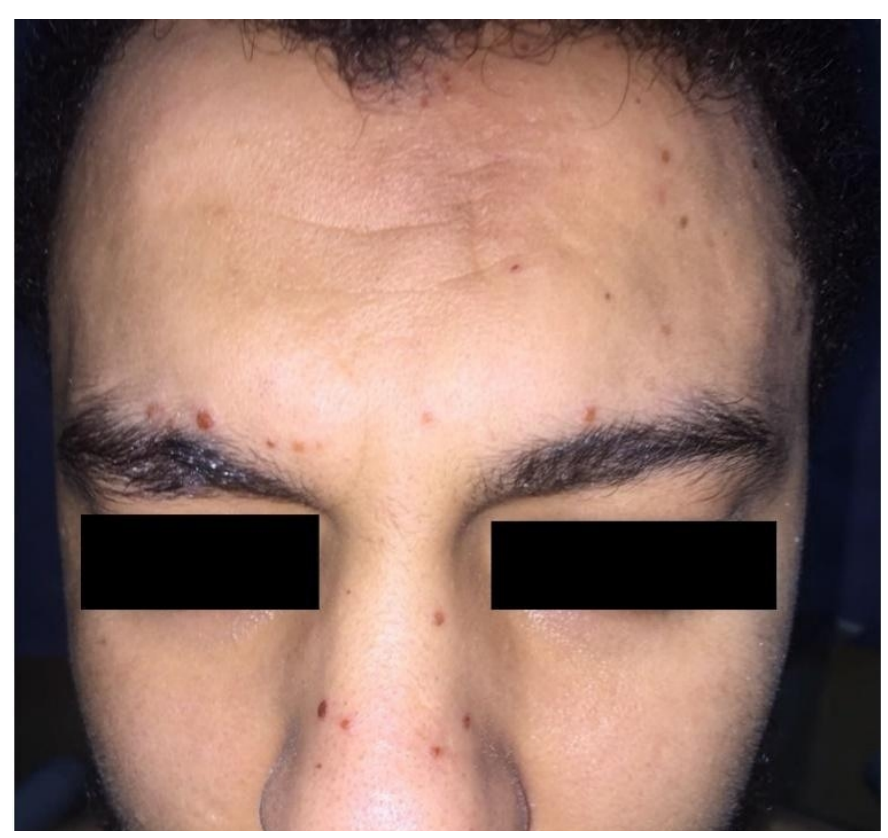

Figure 8. Facial palpable purpuric lesions in a patient with granulomatosis with polyangiitis.

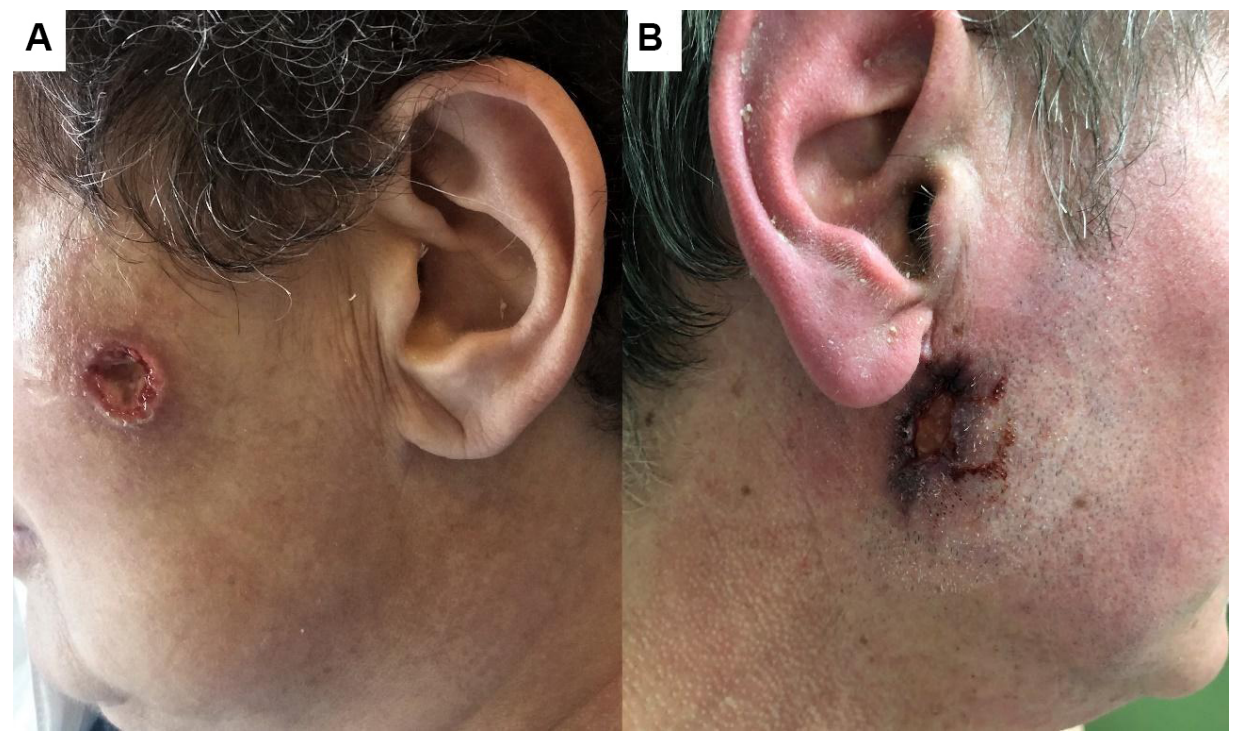

Figure 9. Facial pyoderma gangrenosum similar to ulcers, a rare presentation in two cases of granulomatosis with polyangiitis (courtesy of Dr. Luca Quartuccio, Associate Professor of Rheumatology, Department of Medicine, Udine University and Dr. Enzo Errichetti, Clinic of Dermatology, Department of Medicine, Academic Hospital "Santa Maria della Misericordia" (ASUFC), Udine, Italy).

Other rare vasculitic cutaneous manifestations of GPA include digital or penile ulceration and gangrene $e^{[8,21]}$. McKenney and Siegel ${ }^{[30]}$ described another rare example of cutaneous pathology in GPA. They presented a case with large tender indurated subcutaneous violaceous skin lesion that was initially thought to be a hematoma. The diagnosis was only established following a skin biopsy which revealed perivascular infiltrates and necrotizing granulomas involving small vessels in the subcutaneous septa ${ }^{[30]}$. 
Erythema elevatum diutinum-like nodules and plaques mainly involving the extensor aspects of the limbs with symmetric distribution have been described early in the course of $\mathrm{MPA}^{[31]}$. Digital ischemia and gangrene can also rarely develop in $\mathrm{MPA}^{[4]}$.

\section{Clinical presentation of PNGD which can develop with $A A V$}

The classic clinical presentation of PNGD is erythematous or flesh-colored papules which may develop central umbilication or crustations. They usually take a symmetrical distribution on the extremities, mainly involving elbows and knees and but frequently other $\operatorname{sites}^{[15,32]}$ [Figure 10].

\section{Clinical presentation of non-specific skin lesions in AAV}

Many non-specific skin lesions can occur in AAV patients. Non-specific maculopapular rash is the second most frequently encountered skin manifestation in AAV occurring in $8 \%$ of cases $^{[2]}$. In GPA, non-specific oral lesions develop in 10\%-60\% of patients and may be the presenting sign of the disease in $5 \%$ of cases $^{[33,34]}$. They take the form of oral erosions or ulcers ${ }^{[3]}$ [Figure 11], strawberry gingivitis with exophytic hyperplasia, and mucosal petechial spots and erythematous granular appearance (with or without loss of alveolar bone and loosening of teeth) ${ }^{[33-35]}$. Other non-specific lesions in GPA include skin ulcers (with no pathological evidence of vasculitis or granulomas) ${ }^{[7]}$, erythema nodosum-like lesions ${ }^{[24]}$, xanthelasmas $^{[3]}$, sterile pustules $^{[7]}$, acneiform lesions ${ }^{[36]}$, and chronic eyelid edema and infiltration ${ }^{[37]}$. EGPA patients commonly develop urticarial-like, angioedema-like, erythema multiforme-like, and chronic itchy lichenified prurigo nodularis-like lesions, as well as sterile pustules ${ }^{[1,38]}$. Allergic manifestations such as pruritus are also frequently observed in $\mathrm{EGPA}^{[2,39]}$. Cases of EGPA presenting with Well's syndrome (eosinophilic panniculitis)-like picture have been reported ${ }^{[40]}$. Urticarial lesions may also develop with MPA ${ }^{[4]}$. Table 1 represents a summary of the clinicopathological spectrum of cutaneous lesions in AAV.

\section{CUTANEOUS LESIONS IN RELATION TO DIFFERENT TYPES OF AAV AND DIFFERENT TYPES OF ANCA}

Certain skin lesions were noticed to develop more frequently in certain types of AAV. For example, livedo reticularis/racemosa and segmentary edema develop significantly more frequently in MPA. Non-specific manifestations such as pruritus, urticaria, and maculopapular rash are more likely encountered in EGPA. Urticaria is uncommon in GPA and MPA. Painful skin lesions and skin ulcers occur more significantly in GPA and EGPA when compared to MPA ${ }^{[2,39]}$. Oral ulcers are also more frequently associated with GPA as compared to EGPA and MPA ${ }^{[39]}$. PG-like lesions and palpebral xanthomas can only occur in $\mathrm{GPA}^{[39]}$.

Cutaneous lesions were found to be the presenting manifestation of AAV in patients with positive cytoplasmic/anti-PR3ANCA or in ANCA-negative patients when compared to patients with positive perinuclear/anti-MPO ANCA. The same was observed as regards the development of the typical vasculitic skin lesions of purpura/petechiae and splinter hemorrhages. Coinciding with their significantly higher occurrence in MPA, livedo reticularis/racemosa were reported more often in patients with positive perinuclear/anti-MPO ANCA than in those without. Non-specific manifestations such as pruritus and urticaria were more frequently encountered in ANCA-negative patients. The presence of multiple types of cutaneous manifestations was most frequently reported in patients who were ANCA-negative ${ }^{[2]}$.

\section{CUTANEOUS LESIONS IN RELATION TO SPECIFIC ORGAN INVOLVEMENT AND SEVERITY OF SYSTEMIC MANIFESTATIONS OF AAV}

GPA patients with skin lesions were more prone to have pulmonary, renal, neurologic, musculoskeletal, and gastrointestinal involvement and more severe manifestations ${ }^{[2,39]}$. Similarly, EGPA patients with skin lesions were more likely to suffer from renal, neurologic, musculoskeletal, and gastrointestinal involvement. They 
Table 1. The clinicopathological spectrum of cutaneous lesions in AAV

\begin{tabular}{|c|c|c|}
\hline \multicolumn{2}{|r|}{ Clinical spectrum of skin lesions in AAV } & \multirow[b]{2}{*}{$\begin{array}{l}\text { Underlying histopathological findings } \\
\text { Vasculitis } \\
\text { - LCV } \\
\text { - May be vasculitis with granulomatosis (perivascular } \\
\text { granulomatosis) } \\
\text { With or without } \\
\text { Granulomas } \\
\text { - Necrobiotic palisading/necrotizing granulomas } \\
\text { - Palisaded neutrophilic and granulomatous dermatitis }\end{array}$} \\
\hline Specific lesions & $\begin{array}{l}\text { Palpable purpura/petechia } \\
\text { Livedo reticularis/racemosa } \\
\text { Papules or nodules on purpuric background } \\
\text { Tender subcutaneous nodules } \\
\text { Hemorrhagic blisters } \\
\text { Painful ulcerations (skin necrosis) } \\
\text { Splinter hemorrhages } \\
\text { PG-like ulcers } \\
\text { PNGD } \\
\text { Digital/penile ulcers (or gangrene) } \\
\text { EED-like lesions }\end{array}$ & \\
\hline \multirow[t]{3}{*}{$\begin{array}{l}\text { Non-specific } \\
\text { lesions }\end{array}$} & $\begin{array}{l}\text { GPA } \\
\text { Non-specific maculopapular rash } \\
\text { Oral erosions or ulcers } \\
\text { Strawberry gingivitis with exophytic hyperplasia } \\
\text { Mucosal petechial spots and erythematous granular } \\
\text { appearance } \\
\text { Non-specific skin ulcers } \\
\text { Erythema nodosum-like lesions } \\
\text { Xanthelasmas } \\
\text { Sterile pustules } \\
\text { Acneiform lesions } \\
\text { Chronic eyelid edema and infiltration }\end{array}$ & $\begin{array}{l}\text { No vasculitis } \\
\text { No granulomas } \\
\text { Features of the corresponding clinical entity } \\
\text { Or } \\
\text { Non-specific perivascular lymphocytic infiltrate }\end{array}$ \\
\hline & $\begin{array}{l}\text { EGPA } \\
\text { Non-specific maculopapular rash } \\
\text { Urticarial-like rash } \\
\text { Erythema multiforme-like rash } \\
\text { Chronic itchy lichenified prurigo nodularis-like lesions } \\
\text { Well's syndrome-like lesions } \\
\text { Sterile pustules } \\
\text { Pruritus }\end{array}$ & \\
\hline & $\begin{array}{l}\text { MPA } \\
\text { Non-specific maculopapular rash } \\
\text { Urticarial lesions }\end{array}$ & \\
\hline
\end{tabular}

AAV: ANCA-associated vasculitis; GPA: granulomatosis with polyangiitis; EGPA: eosinophilic granulomatosis with polyangiitis; MPA: microscopic polyangiitis; LCV: leukocytoclastic vasculitis; PG: pyoderma gangrenosum; PNGD: palisaded neutrophilic and granulomatous dermatitis; EED: erythema elevatum diutinum.

also had more severe manifestations ${ }^{[2,39]}$. In a recent study, purpura in patients with EGPA was associated with increased C-reactive protein, interleukin 5, and Birmingham Vasculitis Activity Scores ${ }^{[4]}$. Cutaneous lesions in patients with MPA were usually associated with arthralgia and ophthalmologic involvement ${ }^{[4]}$, and these patients suffered more from neurologic and musculoskeletal manifestations and were less likely to have pulmonary or renal involvement ${ }^{[2]}$. No difference in the severity of the systemic manifestations of MPA was found between patients with or without cutaneous disease ${ }^{[2,39]}$. Cutaneous manifestations were associated with poorer relapse-free and overall survival in GPA when compared to EGPA and MPA ${ }^{[39]}$.

\section{IMPORTANT DIFFERENTIAL DIAGNOSES OF CUTANEOUS LESIONS OF AAV}

Since skin lesions of AAV are non-specific from the point of view that they can develop in other types of vasculitis and in other systemic disorders, careful evaluation of cases presenting with skin lesions is mandatory.

Palpable purpura/petechiae can be seen in all types of cutaneous vasculitis including allergic vasculitis (triggered by infections or drugs or occurring as an idiopathic disorder), Henoch-Schönlein purpura, and cutaneous vasculitis in collagen diseases. Proper history taking, clinical verification of visceral involvement, and laboratory and serological investigations can help to correctly diagnose such cases. The detection of IgA deposits by DIF is characteristic of Henoch-Schönlein purpura, which also presents with renal involvement, 


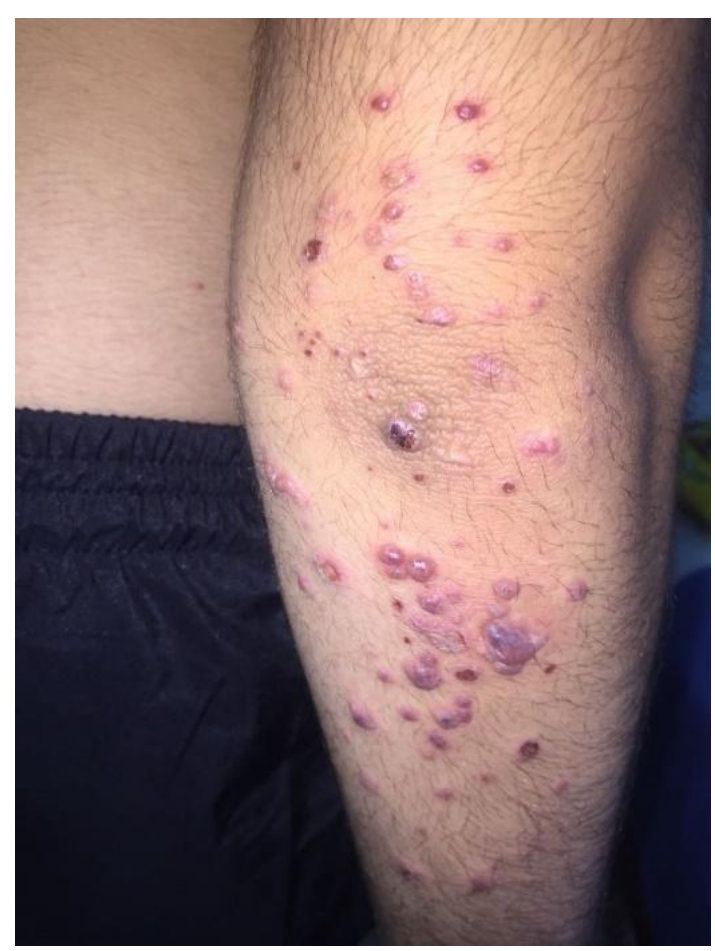

Figure 10. Palisaded neutrophilic and granulomatous dermatitis presenting as papules with central necrosis in a patient with granulomatosis with polyangiitis.

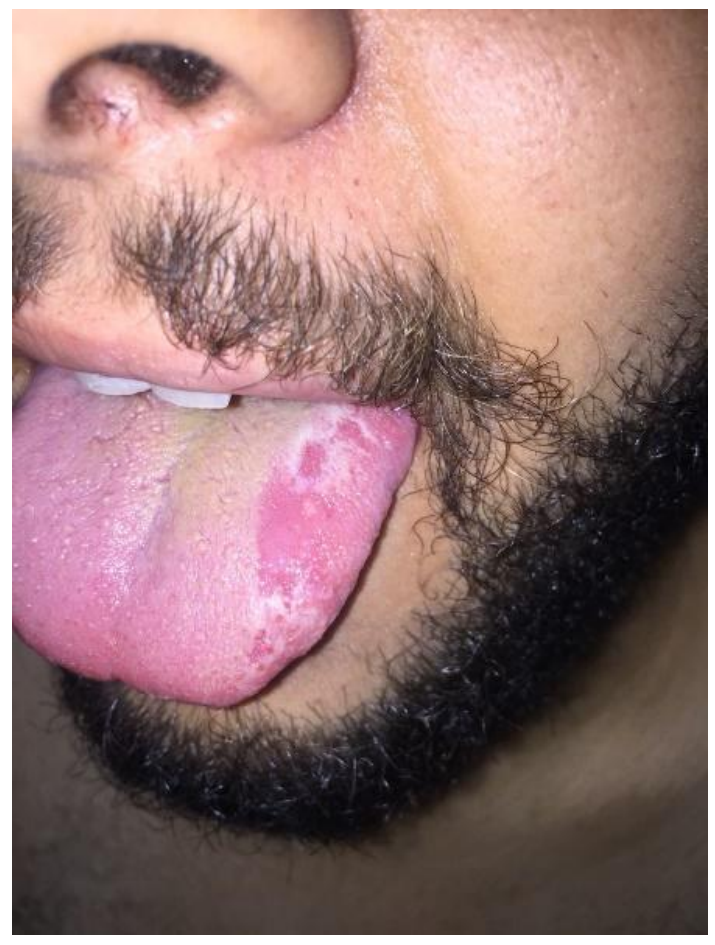

Figure 11. Non-specific oral erosions in a patient with GPA.

creating possible clinical confusion with $\mathrm{AAV}^{[42]}$. 
The presence of associated skin necrosis, ulceration, and gangrenes in the context of palpable purpuric lesions warrants exclusion of other conditions such as hepatitis $C$ virus-induced vasculitis other causes of cryoglobulinemic vasculitis and vasculitis associated with underlying vasculopathic disorders such as protein $\mathrm{C}$ and $\mathrm{S}$ deficiency or factor $\mathrm{V}$ Leiden mutation $^{[43]}$. Livedo reticularis/racemosa and skin nodules can also be a manifestation of polyarteritis nodosa ${ }^{[4]}$.

Localized cases of GPA involving mainly the face, nose, ears, and throat should be differentiated from levamisole induced vasculopathy associated with levamisole-adulterated cocaine abuse. History taking, skin biopsy findings, and negative ANCA can help in verifying this condition ${ }^{[44]}$.

PG-like lesions of GPA should be differentiated from classic PG. The presence of cytoplasmic/anti-PR3ANCA, the involvement of internal organs (mainly the lungs), the presence of palisaded neutrophilic and granulomatous dermatitis, necrotizing vasculitis and basophilic collagen degeneration on skin biopsy, and not diffuse neutrophilic infiltrate helps in excluding classic PG in such cases ${ }^{[45]}$. Cultures to exclude infectious causes are also important in PG-like lesions or in cases presenting with ulcerated nodules/plaques that show granulomatous inflammation on biopsy. Finally, many types of cutaneous lymphomas can present as PG-like lesions ${ }^{[46]}$, and a skin biopsy will easily establish the diagnosis.

It is important also to remember that lesions of PNGD can occur in association with a wide range of systemic disorders other than AAV such as connective tissue disorders, arthritides, Behçet's disease, ulcerative colitis, lymphoproliferative disorders, and multiple sclerosis ${ }^{[15,47,48]}$. Careful clinical, laboratory, and serological assessment is important in such cases.

Finally, care should be given not to confuse vasculitic lesions of AAV with hemorrhagic or occlusive pseudovasculitis. Hemorrhagic pseudovasculitis presents with non-palpable petechiae, purpura, or ecchymoses as a result of vessel wall dysfunction that can occur in many conditions such as metabolic disorders, nutritional deficiencies, drug reactions, infections, thrombocytopenias, or simply with aging. Occlusive pseudovasculitis on the other hand presents with livedo, acral cyanosis, or digital necrosis/gangrene as a result of occlusion of vessel lumen by emboli, thrombi, or other materials. Examples of occlusive pseudovasculitis include essential cryoglobulinemia, purpura fulminans, coumadin necrosis, antiphospholipid syndrome, cardiac myxoma, calciphylaxis, cholesterol embolization, and radiation $\operatorname{arteritis}^{[49]}$. In all cases, a skin biopsy and laboratory investigations can easily verify such conditions.

\section{MANAGEMENT OF CUTANEOUS LESIONS OF AAV}

AAV patients presenting with skin manifestations should follow the same standard algorithms and guidelines of management used in patients without cutaneous manifestations. These include measures to induce remission of new-onset organ threatening (life threatening) or non-organ threatening disease, as well as measures to induce remissions of relapses and measures to maintain remissions ${ }^{[50]}$.

Although skin ulcers if present can become contaminated with different types of bacteria, routine administration of topical or systemic antibiotics is not encouraged, as it was not found to be associated with reduced bacterial colonization or better healing and can lead to emergence of resistant strain ${ }^{[51]}$. Systemic and non-topical antibiotics are recommended only in the presence of significant evidence of infection such as increasing pain, erythema in the surrounding skin, progressive increase in ulcer size, pus discharge, hotness, or edema ${ }^{[52]}$. Proper management of ulcers should also include removal of necrotic tissue by surgical or chemical debridement and the use of appropriate dressings such as hydrocolloid and hydrogel sheets which absorb fluids from the wound and keep it moist ${ }^{[53,54]}$. Pain relief measures should also be 
considered and tailored according to the needs of each patient in a way that improves his/her quality of life $\mathrm{e}^{[55]}$.

\section{CONCLUSION}

Cutaneous manifestations are common in AAV. They may be the presenting manifestation of the disease, occur during its course, or mark a disease relapse. They may be specific or non-specific according to the presence or absence of vasculitis with or without granulomas in skin biopsies. They are usually associated with severe systemic manifestations and multiple organ involvement. Since such lesions can occur in other types of systemic vasculitis and in other disorders, linking them with AAV requires meticulous clinical, laboratory, and serological correlation.

\section{DECLARATIONS}

\section{Authors' contributions}

Made substantial contributions to conception and design of the manuscript, writing, editing, provision of clinical photos and histopathological photomicrographs: Abdel-Halim M

Contributed to writing the manuscript: Mahmoud A

Planning, supervising, revision of the manuscript and editing: Ragab G

\section{Availability of data and materials}

Not applicable.

\section{Financial support and sponsorship}

None.

\section{Conflicts of interest}

All authors declared that there are no conflicts of interest.

\section{Ethical approval and consent to participate}

Not applicable.

\section{Consent for publication}

Not applicable.

\section{Copyright}

(c) The Author(s) 2022.

\section{REFERENCES}

1. Cornec D, Cornec-Le Gall E, Fervenza FC, Specks U. ANCA-associated vasculitis - clinical utility of using ANCA specificity to classify patients. Nat Rev Rheumatol 2016;12:570-9. DOI PubMed

2. Micheletti RG, Chiesa Fuxench Z, Craven A, Watts RA, Luqmani RA, Merkel PA; DCVAS Investigators. Cutaneous manifestations of antineutrophil cytoplasmic antibody-associated vasculitis. Arthritis Rheumatol 2020;72:1741-7. DOI PubMed

3. Francès C, Du LT, Piette JC, et al. Wegener's granulomatosis. Dermatological manifestations in 75 cases with clinicopathologic correlation. Arch Dermatol 1994;130:861-7. PubMed

4. Kluger N, Pagnoux C, Guillevin L, Francès C; French Vasculitis Study Group. Comparison of cutaneous manifestations in systemic polyarteritis nodosa and microscopic polyangiitis. Br J Dermatol 2008;159:615-20. DOI PubMed

5. Comarmond C, Pagnoux C, Khellaf M, et al; French Vasculitis Study Group. Eosinophilic granulomatosis with polyangiitis (ChurgStrauss): clinical characteristics and long-term followup of the 383 patients enrolled in the French Vasculitis Study Group cohort. Arthritis Rheum 2013;65:270-81. DOI PubMed

6. Ragab G, Hegazy MT, Ali M, Abdel-Halim MRE, Puéchal X. Three patterns of cutaneous involvement in granulomatosis with polyangiitis. J Adv Res 2020;24:311-5. DOI PubMed PMC

7. Daoud MS, Gibson LE, Deremee RA, Specks U, el-Azhary RA, Daniel Su W. Cutaneous Wegener's granulomatosis: clinical, histopathologic, and immunopathologic features of thirty patients. J Am Acad Dermatol 1994;31:605-12. DOI PubMed 
8. Marzano AV, Vezzoli P, Berti E. Skin involvement in cutaneous and systemic vasculitis. Autoimmun Rev 2013;12:467-76. DOI PubMed

9. Barksdale SK, Hallahan CW, Kerr GS, Fauci AS, Stern JB, Travis WD. Cutaneous pathology in Wegener's granulomatosis. A clinicopathologic study of 75 biopsies in 46 patients. Am J Surg Pathol 1995;19:161-72. PubMed

10. Chanda JJ, Callen JP. Necrotizing vasculitis (angiitis) with granulomatosis. Int J Dermatol 1984;23:101-7. DOI PubMed

11. Yevich I. Necrotizing vasculitis with granulomatosis. Int J Dermatol 1988;27:540-6. DOI PubMed

12. Hoekstra JA, Fauci AS. The granulomatous vasculitides. Clin Rheum Dis 1980;6:373-88.

13. Decleva I, Marzano AV, Barbareschi M, Berti E. Cutaneous manifestations in systemic vasculitis. Clin Rev Allergy Immunol 1997;15:5-20. DOI PubMed

14. Seishima M, Oyama Z, Oda M. Skin eruptions associated with microscopic polyangiitis. Eur J Dermatol 2004;14:255-58. PubMed

15. Finan MC, Winkelmann RK. The cutaneous extravascular necrotizing granuloma (Churg-Strauss granuloma) and systemic disease: a review of 27 cases. Medicine (Baltimore) 1983;62:142-58. DOI PubMed

16. Hunt RD, Hartman RD, Molho-Pessach V, Votava HJ, Schaffer JV. Palisaded neutrophilic and granulomatous dermatitis in an adolescent girl with perinuclear antineutrophil cytoplasmic antibody-positive pauci-immune glomerulonephritis and arthritis. $J \mathrm{Am}$ Acad Dermatol 2012;67:e164-6. DOI PubMed

17. Chu P, Connolly MK, LeBoit PE. The histopathologic spectrum of palisaded neutrophilic and granulomatous dermatitis in patients with collagen vascular disease. Arch Dermatol 1994;130:1278-83. PubMed

18. Iudici M, Pagnoux C, Courvoisier DS, et al; French Vasculitis Study Group. Granulomatosis with polyangiitis: study of 795 patients from the French Vasculitis Study Group registry. Semin Arthritis Rheum 2021;51:339-46. DOI PubMed

19. Marzano AV, Raimondo MG, Berti E, Meroni PL, Ingegnoli F. Cutaneous manifestations of ANCA-associated small vessels vasculitis. Clin Rev Allergy Immunol 2017;53:428-38. DOI PubMed

20. Patten SF, Tomecki KJ. Wegener's granulomatosis: cutaneous and oral mucosal disease. J Am Acad Dermatol 1993;28:710-8. DOI PubMed

21. Comarmond C, Cacoub P. Granulomatosis with polyangiitis (Wegener): clinical aspects and treatment. Autoimmun Rev 2014;13:11215. DOI PubMed

22. Tashtoush B, Memarpour R, Johnston Y, Ramirez J. Large pyoderma gangrenosum-like ulcers: a rare presentation of granulomatosis with polyangiitis. Case Rep Rheumatol 2014;2014:850364. DOI PubMed PMC

23. Semo R, Tal R, Dallos T, Harel L, Plank L, Wagner-Weiner L. Pyoderma gangrenosum ulceration as a presenting feature of pediatric granulomatosis with polyangiitis (GPA) [abstract]. Arthritis Rheumatol 2020;72. DOI

24. Comfere NI, Macaron NC, Gibson LE. Cutaneous manifestations of Wegener's granulomatosis: a clinicopathologic study of 17 patients and correlation to antineutrophil cytoplasmic antibody status. J Cutan Pathol 2007;34:739-47. DOI PubMed

25. Chyu JY, Hagstrom WJ, Soltani K, Faibisoff B, Whitney DH. Wegener's granulomatosis in childhood: cutaneous manifestations as the presenting signs. J Am Acad Dermatol 1984;10:341-6. DOI PubMed

26. Kass A, Fagan JD, Long P. Granulomatosis with polyangiitis presenting with pyoderma gangrenosum-like ulceration and negative cytoplasmic antineutrophilic cytoplasmic antibodies in a child. Pediatr Dermatol 2017;34:e231-4. DOI PubMed

27. Moen BH, Nystad TW, Barrett TM, Sandvik LF. A boy in his teens with large ulcerations of the head and neck. Tidsskr Nor Laegeforen 2019:139. DOI PubMed

28. Holle JU, Gross WL, Holl-Ulrich K, et al. Prospective long-term follow-up of patients with localised Wegener's granulomatosis: does it occur as persistent disease stage? Ann Rheum Dis 2010;69:1934-9. DOI PubMed

29. Marzano AV, Balice Y, Papini M, Testa R, Berti E, Crosti C. Localized Wegener's granulomatosis. J Eur Acad Dermatol Venereol 2011;25:1466-70. DOI PubMed

30. McKenney DW, Siegel NJ. An unusual skin lesion in a pediatric patient with Wegener's granulomatosis. Pediatr Nephrol 1994;8:5878. DOI PubMed

31. Marzano AV, Ishak RS, Saibeni S, Crosti C, Meroni PL, Cugno M. Autoinflammatory skin disorders in inflammatory bowel diseases, pyoderma gangrenosum and Sweet's syndrome: a comprehensive review and disease classification criteria. Clin Rev Allergy Immunol 2013;45:202-10. DOI PubMed

32. Huizenga T, Kado JA, Pellicane B, Borovicka J, Mehregan DR, Mehregan DA. Interstitial granulomatous dermatitis and palisaded neutrophilic granulomatous dermatitis. Cutis 2018;101:E19-21. PubMed

33. Stewart C, Cohen D, Bhattacharyya I, et al. Oral manifestations of Wegener's granulomatosis: a report of three cases and a literature review. J Am Dent Assoc 2007;138:338-48; quiz 396, 398. DOI PubMed

34. Ruokonen H, Helve T, Arola J, Hietanen J, Lindqvist C, Hagstrom J. "Strawberry like" gingivitis being the first sign of Wegener's granulomatosis. Eur J Intern Med 2009;20:651-3. DOI PubMed

35. Manchanda Y, Tejasvi T, Handa R, Ramam M. Strawberry gingiva: a distinctive sign in wegener's granulomatosis. $J$ Am Acad Dermatol 2003;49:335-7. DOI PubMed

36. Wright AC, Gibson LE, Davis DM. Cutaneous manifestations of pediatric granulomatosis with polyangiitis: a clinicopathologic and immunopathologic analysis. J Am Acad Dermatol 2015;72:859-67. DOI PubMed

37. Gajic-Veljic M, Nikolic M, Peco-Antic A, Bogdanovic R, Andrejevic S, Bonaci-Nikolic B. Granulomatosis with polyangiitis (Wegener's granulomatosis) in children: report of three cases with cutaneous manifestations and literature review. Pediatr Dermatol 2013;30:e37-42. DOI PubMed

38. Morita TCAB, Criado PR, Criado RFJ, Trés GFS, Sotto MN. Update on vasculitis: overview and relevant dermatological aspects for the clinical and histopathological diagnosis - part II. An Bras Dermatol 2020;95:493-507. DOI PubMed PMC 
39. Frumholtz L, Laurent-Roussel S, Aumaître O, et al; French Vasculitis Study Group. Clinical and pathological significance of cutaneous manifestations in ANCA-associated vasculitides. Autoimmun Rev 2017;16:1138-46. DOI PubMed

40. Omiya W, Fujita Y, Baba K, Shibaki A, Odani T, Shimizu H. Unusual cutaneous manifestations of Churg-Strauss syndrome mimicking Wells' syndrome. Eur J Dermatol 2012;22:576-8. DOI PubMed

41. Kataoka H, Tomita T, Kondo M, Mukai M. Presence of purpura is related to active inflammation in association with IL-5 in eosinophilic granulomatosis with polyangiitis. Rheumatol Int 2021;41:449-54. DOI PubMed PMC

42. Saulsbury FT. Clinical update: Henoch-Schönlein purpura. Lancet 2007;369:976-8. DOI PubMed

43. Marković A. Vasculitis and vasculopathy. Acta Med Croatica 2012;66:19-24. (in Croatian). PubMed

44. Rachapalli SM, Kiely PD. Cocaine-induced midline destructive lesions mimicking ENT-limited Wegener's granulomatosis. Scand J Rheumatol 2008;37:477-80. DOI PubMed

45. Weenig RH, Davis MD, Dahl PR, Su WP. Skin ulcers misdiagnosed as pyoderma gangrenosum. $N$ Engl J Med 2002;347:1412-8. DOI PubMed

46. Cozzani E, Scaparro M, Rongioletti F, Pierri I, Pimpinelli N, Parodi A. Pyoderma gangrenosum-like CD30+ cutaneous T-cell lymphoma in a patient with mycosis fungoides. J Eur Acad Dermatol Venereol 2015;29:819-21. DOI PubMed

47. Kim SK, Park CK, Park YW, Jun JB, Yoo DH, Bae SC. Palisaded neutrophilic granulomatous dermatitis presenting as an unusual skin manifestation in a patient with Behçet's disease. Scand J Rheumatol 2005;34:324-7. DOI PubMed

48. Hantash BM, Chiang D, Kohler S, Fiorentino D. Palisaded neutrophilic and granulomatous dermatitis associated with limited systemic sclerosis. J Am Acad Dermatol 2008;58:661-4. DOI PubMed

49. Carlson JA, Chen KR. Cutaneous pseudovasculitis. Am J Dermatopathol 2007;29:44-55. DOI PubMed

50. Yates M, Watts RA, Bajema IM, et al. EULAR/ERA-EDTA recommendations for the management of ANCA-associated vasculitis. Ann Rheum Dis 2016;75:1583-94. DOI PubMed

51. Alinovi A, Bassissi P, Pini M. Systemic administration of antibiotics in the management of venous ulcers. $J$ Am Acad Dermatol 1986;15:186-91. DOI PubMed

52. O'Meara S, Al-Kurdi D, Ologun Y, Ovington LG, Martyn-St James M, Richardson R. Antibiotics and antiseptics for venous leg ulcers. Cochrane Database Syst Rev 2014;1:CD003557. DOI PubMed

53. Madhok BM, Vowden K, Vowden P. New techniques for wound debridement. Int Wound J 2013;10:247-51. DOI PubMed PMC

54. Armitage M, Roberts J. Caring for patients with leg ulcers and an underlying vasculitic condition. Br J Community Nurs 2004;:Suppl:S16-22. DOI PubMed

55. Briggs M, Ferris FD, Glynn C, et al. Assessing pain at wound dressing-related procedures. Nurs Times 2004;100:56-7. PubMed 